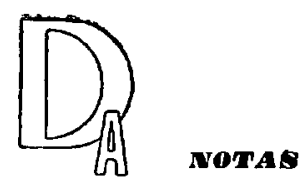

\title{
OBSERVACIONES A LOS CONCURSOS DE MERITOS 1/1966 Y 1/1967
}

Por LUIS BLANCO DE TELLA

$35.082 .33(46)$

1. El examen de los anexos que acompañan a las órdenes de 10 de agosto de 1966, por las que se convocaron concursos de méritos para la provisión de plazas vacantes del Cuerpo General Administrativo, Cuerpo General Auxiliar y Cuerpo General Técnico (se citan siguiendo el orden de inserción en el Boletin Oficial del Estado), y a las de 18 de enero del corriente año, anunciando los recientes concursos 1/1967, para los mismos cuerpos indicados, plantea, a nuestro modo de ver, ciertos problemas que pueden afectar a la claridad indispensable en disposiciones de esta clase.

Nos referimos, en concreto, a la expresión de méritos preferentes incluidos en los citados anexos a propuesta de los departamentos ministeriales interesačos, en virtud de lo dispuesto en el articulo 58-2 de la Ley articulada de Funcionarios Civiles del Estado y artículo 9. 
DA-1967, núm. 109. LUIS BLANCO DE TELLA. Observaciones a los concursos de méritos 1/1966 y...

del decreto $1106 / 1966$, de 28 de abril, por el que se reglamenta la provisión de vacantes correspondientes a los Cuerpos Generales. Dicha expresión aparece realizada en ocasiones con tal imprecisión y falta de tecnicismo que para ciertos méritos resulta realmente difícil buscar un adecuado encaje en el baremo de puntuación vigente (anexo 1 del citado decreto 1106/1966).

Es cierto que los méritos preferentes «podrán ser cualesquiera que el departamento ministerial proponga como convenientes, incluso los ajenos a los requeridos para la pertenencia al Cuerpo a cuya vacante se concurra》 (art. 9-1 del repetido decreto 1106/1966), pero esta libertad no autoriza la indeterminación y vaguedad que se aprecia en clertos casos, y debe, por otra parte, entenderse encuadrada dentro del marco establecido en el articulo 10 del mismo decreto, a cuyo tenor "cuando los ministerios hagan uso de la facultad señalada en el artículo 9. ${ }^{\circ}$, la valoración de los méritos con arreglo al baremo establecido en el anexo 1 se efectuará una vez comprobado que quienes aspiren a las plazas para las que se han establecido reúnen las condiciones, méritos o requisitos necesarios».

2. La primera duda que se nos plantea a la vista de este precepto hace referencia a la valoración que procede realizar cuando se incluyen en la convocatoria, como méritos preferentes, conocimientos propios del Cuerpo al que las plazas anunciadas pertenecen. Así, por ejemplo, declarar mérito preferente, o incluso condición excluyente (conservamos la defectuosa expresion que utilizan las disposiciones citadas), el conocimiento de la mecanografia, para determinadas vacantes del Cuerpo Auxiliar, puede parecer poco congruente con el texto del artículo 23-5 de la Ley de Funcionarios civiles, pues dicha actividad se configura como propia de los miembros del indicado Cuerpo. En todo caso, tales méritos, si es que así pueden calificarse, plantean problemas de valoración al no encajar en ninguno de los seis apartados del baremo previsto para el Cuerpo Auxiliar.

3. Por otra parte, tampoco vemos posibilidad de aplicar el citado baremo de puntuación a ciertos títulos, diplomas o conocimientos especiales que en las dos convocatorias aparecidas hasta la fecha se han incluido con el carácter de mérito preferente para determinadas plazas del repetido Cuerpo. Tales son, por ejemplo:

- Diploma oficial que acredite el dominio de la taquigrafía.

- Diploma que acredite el conocimiento de la estenotipia.

- Conocimientos de estadistica.

- Traducir y escribir francés.

- Hablar, traducir y escribir inglës. 
DA-1967, núm. 109. LUIS BLANCO DE TELLA. Observaciones a los concursos de méritos 1/1966 y...

Todo ello resultaría fácilmente calificable en el caso de existir, dentro del baremo a que se hace referencia, un epigrafe específico que permitiera asignar un valor determinado a los conocimientos 0 estudios relacionados con la Administración pública, a semejanza de lo que ocurre con los baremos aplicables å los Cuerpos Técnico y Administrativo (epigrafes $50^{\circ}$ y $4 .^{\circ}$, respectivamente).

4. En otros casos los problemas de valoración no derivan sólo de la insuficiencia del baremo, sino también de la oscuridad e indeterminación de la expresión utilizada para señalar los méritos preferentes. Asi, ocurre, por ejemplo, con los casos siguientes:

- Tener conocimientos elementales de la Administración en general.

- Conocer la organización de oficinas y la Administración.

Tales expresiones resultan lo suficientemente borrosas como para no requerir mayores comentarios.

5. El punto que creemos merece mayor atención es, no obstante, el relativo a la inclusión de determinados cursos en concepto de mérito preferente. Es innegable que en algunos casos tal inclusión aparece realizada con toda la precisión deseable. Asi, para ciertas plazas del Cuerpo Técnico:

- Curso monográfico de Administración de personal en la Escuela Nacional de Administración Pública.

- Curso de formación (para técnicos de Administración civil) en la Escuela Nacional de Administración Pública.

- Diploma de Organización y Métodos.

Sin embargo, esta claridad no es la regla general, sino la excepción. Lo normal es que la indicación de los cursos a los que se atribuye valor de mérito preferente se realice de forma confusa o indeterminada. En algunos casos no se hace constar si la exigencia se refiere a cursos desarrollados en la Escuela Nacional de Administración Pública o si abarca también los organizados por otros centros de enseñanza. En otros supuestos, aun señalándose expresamente aquella circunstancia, no se precisa la clase de curso de que se trata, pareciendo darse por supuesto que todos ellos sirven aproximadamente para lo mismo, cualesquiera que sean las materias tratadas o la extensión del periodo lectivo. Como prueba de lo anterior pueden verse los siguientes ejemplos:

- Para una vacante del Cuerpo General Técnico, en el Ministerio de Agricultura, concurso 1/1967: Cursos en la Escuela Nacional 
DA-1967, núm. 109. LUIS BLANCO DE TELLA. Observaciones a los concursos de méritos 1/1966 y...

de Administración Pública. La indeterminación, en este caso, es máxima. No se expresa si se trata del curso de formación o de cursos de perfeccionamiento, generales, especiales o monográficos.

- Para una vacante del Cuerpo General Técnico, en el Ministerio de Educación y Ciencia, concurso 1/1967: Estar en posesión del diploma de Organización y Métodos o certificados sobre asistencia a cursos sobre organización y mecanización administrativa. Nada hay que objetar por lo que se refiere al citado diploma, pero si en lo que respecta a los certificados de asistencia a cursos sobre organización y mecanización, ya que no conocemos ningún curso convocado por la ENAP bajo dicha denominación o limitado a tales materias. Claro es que el anuncio tampoco manifiesta que se trate de cursos organizados por dicha entidad.

- Para una vacante del Cuerpo General Técnico, en el Ministerio de Educación y Ciencia, concurso 1/1966: Haber realizado estudios sobre principios básicos de Organización $y$ Métodos. Aunque no se expresa exigencia alguna en cuanto al lugar de desarrollo de tales estudios, es de señalar que la ENAP no ha publicado hasta la fecha ninguna convocatoria de cursos de dicha clase. La denominación utilizada en este caso sólo ha sido aplicada en los origenes de la ENAP a ciertos ciclos elementales de diez horas de duración total.

- Para una vacante del Cuerpo General Técnico en la Presidencia del Gobierno, concurso 1/1966: Haber realizado cursos de perfeccionamiento en la Escuela Nacional de Administración Priblica (Centro de Formación y Perfeccionamiento de Funcionarios). No se expresa si se trata del curso general de perfeccionamiento para funcionarios del Cuerpo Técnico de Administración Civil o si es igualmente válido cualquiera de los especiales o monográficos que sobre muy variadas materias se vienen celebrando para el citado Cuerpo. Cierta precisión en este punto parece indispensable desde el momento en que dichas modalidades existen dentro de la misma rubbrica general cursos de perfeccionamiento.

- Para siete vacantes del Cuerpo General Técnico en la Presidencia del Gobierno, concurso 1/1967: Cursos en el Instituto de Desarrollo Económico en la Escuela Nacional de Administración Pública. No se indica si se trata solamente del curso general que dicho instituto organiza periódicamente o si sirve 
DA-1967, núm. 109. LUIS BLANCO DE TELLA. Observaciones a los concursos de méritos 1/1966 y...

también algún curso monográfico sobre materias concretas (por ejemplo, programación lineal).

- Para una vacante del Cuerpo General Auxiliar, en la Presidencia del Gobierno, concurso 1/1967: Haber realizado un curso sobre archivo. La Escuela Nacional de Administración Pública no ha celebrado aún ningún curso de dicha clase para ningún Cuerpo. Claro que, en este caso, la convocatoria no exige que dicho curso haya tenido lugar en la ENAP.

- Para todas las vacantes correspondientes al Cuerpo General Auxiliar, en el Ministerio de Trabajo, concurso 1/1967: Haber realizado cursos de secretariado. Tampoco se expresa dónde, aunque en este caso, y a diferencia de lo que ocurre en el anterior, la ENAP ha desarrollado, previa la convocatoria oportuna, cursos de dicha clase y dirigidos exclusivamente a funcionarios del citado Cuerpo.

6. Como conclusión creemos que en esta materia es deseable un grado superior de claridad y concreción. Por una parte, la variedad de cursos que la ENAP programa y desarrolla pueden ajustarse a las necesidades especificas de ciertos puestos de trabajo, lo cual aconseja mayor rigor en el señalamiento de méritos preferentes. Por otro lado, no parece justo atribuir una misma valoración (0,15 puntos) a cursos cuya duración aproximada es de 200 horas lectivas (es el caso, por ejemplo, de los cursos generales del Instituto de Desarrollo Económico) y a ciclos cuya duración total no sobrepasa las 50 horas (cursos generales de perfeccionamiento). Una revisión del baremo puede traducirse en valoraciones más exactas.

La inclusión, en la escala de méritos puntuables reservada al Cuerpo General Auxiliar, de un concepto en el que puedan encajarse los estudios, titulos y diplomas de interés para la Administración, se estima igualmente como modificación aconsejable.

Seria ventajosa, del mismo modo, una mayor tipicidad de los cursos y, a ser posible, la adopción de una clave que permita a los departamentos ministeriales la elección de la clase de curso considerada conveniente por razón de la materia y de su extensión, facilitando igualmente al organismo calificador la identificación y valoración de cada variedad concreta. 
.DA-1967, núm. 109. LUIS BLANCO DE TELLA. Observaciones a los concursos de méritos 1/1966 y...

DA:1967, núm. 109. LUIS BLANCO DE TELLA. Observaciones a los concursos de méritos 1/1966 y... 